\title{
Resilient Learning
}

\section{Towards Integration of Strategic Research Programmes, Higher Education Functions and Regional-National Development}

\author{
https://doi.org/10.3991/ijep.v7i2.6871 \\ Rauno Ilmari Pirinen \\ Laurea University of Applied Sciences, Espoo, Finland \\ rauno.pirinen@laurea.fi
}

\begin{abstract}
In this study, the concept of Learning by Research and Development $(\mathrm{R} \& \mathrm{D})$ is furthered to the world of more resilient learning in the setting of security related $\mathrm{R} \& \mathrm{D}$ projects for development of co-creative products, services and action competence. The background of this study includes an interdisciplinary combination of service science, security, computer science, pedagogy, engineering, and management science. The interdisciplinary combination involves researchers, learners, teachers, and other participants connecting and integrating the academic disciplines, professions, and technologies, along with their methods and perspectives for co-creation of a common goal. This goal emphasizes results as high-value impacts, as well as the value of products, services, and innovations as "deliverables" of the integrative learning process. Until recently, the Learning by R\&D model is clear and transparent; as such, it can be adopted by learning and R\&D integration of other sciences and higher education institutions. The structure of the model is also easy to adapt and renew in case of a change, which means that it can develop from the inside on the one hand, and produce interactions, adaptions, resilience and innovations on the other.
\end{abstract}

Keywords-adaption, deliverable, integrative learning, resilience, resilient learning, scope, situated learning and participation

\section{Introduction}

Integration of externally funded and critical national Research and Development (R\&D) functions and its results and deliverables for high-value impacts in higher education institution is a complex and interaction-based process, not only within technology, but merged with the economic, legislative, and social environments, where the R\&D integration is also influenced by government policy and programmes, financial instruments, laws and regulations, and economic boundary conditions. In this study, the investigation of higher education functions and EU research system is addressed to collective contribution of: 1) knowledge, 2) competence, 3) capability, 4) operative performance, 5) action proficiency, 6) adaptive capability, and 7) resilience. 
In higher education institutions, research activities and achieved high-value impacts by adaptive capability and resilience have become globally important for regionalnational development [1] and societies due to the requirement of mutability of new competence and competent networking experts to meet and adapt current and future challenges [2] and manners of learning [3].

In this view of integration of higher education, externally funded $R \& D$ and regional-national development; Learning by $R \& D$ is a pedagogical and collective approach in which learning is linked to applied R\&D projects and development culture [4]. This indicates that learning expertise arises from social interaction, reflection, knowledge and competence sharing, researching, and solutions-finding of shared agenda-based R\&D objects, such as "learning scopes" and collective adaption and co-creation of R\&D "deliverables". The integrative model emphasizes cooperation and creating learning by "research and development path-dependencies" [5] and makes it possible to include and use various scientific perspectives and methods of learning especially for action-related competence and divergent continuums of studies and R\&D projects. The genealogy and path-dependency of Learning by R\&D concept development is described in followed publications: Research Framework of Integrative Action [6]; Externally Funded Research and Development Projects in Perspective of Learning [4]; and dissertation namely Towards Realization of Research and Development in a University of Applied Sciences [5].

It is frequently impossible to clearly define the work objectives as " $R \& D$ related learning scopes" in advance, and they are instead specified throughout the solutiondevelopment process. The R\&D related learning process requires critical thought strategies and skills for justifying solutions, resilient dimensions and designing of evidence evaluation. Usually, work of R\&D consists of a multidisciplinary setting, continuous solution-development process, focusing on research, development, and generating new competence and action related capabilities. The end results as "deliverables" can be, e.g., a creation, an artifact, a new operating method, an improved methodology, a model, an action capability, a service, or a product as evidence, which is achieved by integrating learning and $\mathrm{R} \& \mathrm{D}$. The most related and reflected literature followed: the new production of knowledge [7]; experiential learning [8]; the critical theory of adult learning [9]; action learning [10]; and learning by expanding as an activity-theoretical approach [11].

One based assumption of study is that realization of regional-national development, R\&D, and its leadership-management functions are rather far from a linearnormative process; instead, this political-decision-making setting is shared by the results of dynamic $\mathrm{R} \& \mathrm{D}$ processes that involve interactions between several actors (see Fig.1) and things that no single actor, such as one higher education institution, can achieve or manage alone [12]. However, the integrative model and collective resilient learning perspective can face a high level of uncertainty, unexpected events, and rival implementation models, e.g., "a separation model" where only high performance units and selected scopes are involved in funded R\&D and regional-national development within dedicated actors' networks and higher education institutions.

In this study, the term "resilient learning" is related to the increased rate of interactions and external R\&D pipelines as more resilient scopes and deliverables for evi- 
dence of lessons learnt and catalytic agents in a processes which shares that knowledge and higher education can be preserved as a service, methodology, product, activity, capability, demand of change, required adaption, performance, policy, or as educational, innovative, or intellectual assets which can be exported for a high value and impact returns as in resonance with the utility related Humboldtian university model; the school as a centre of inquiry [13]; metaphors of learning [14]; situated learning [3]; and interaction between learning and development [15].

In the continuum of this study, the terms "integration" and "integrative learning" address an interactive way of learning where an individual learns along with a workplace, institution, school, and R\&D community, such as an international research consortium, as well as alongside a learning organization and across borders and disciplinary silos, as in a collective learning space that can be regional or individual-global oriented [6]. In this setting, the term "learner" refers to a student, teacher, researcher, decision-maker, participant, or even artifact such as "an intelligence as system based to Bayesian belief network" which can enrich the learner's own decisions through collaborative R\&D by sharing knowledge and expertise and learning from others where R\&D collaboration for learning is used. "Student" is used to indicate that a person is registered as a student in the database of the national Ministry of Education and Culture.

The role of term "resilience" in this study is imperative because it can be expected to further our surviving capabilities by related changes on demand and furthering of novel learning designs and curriculums. This learning design as "resilient learning" concept with address what we need to study when faced with inevitable difficulties, such as often scopes described are in national strategic research agenda and H2020 calls: as grounded so far, the emerging concept of "resilient learning" is approached for achievements of surviving capabilities for changes on demand and manners to enhance the capability at all levels of activities to create paths that are robust yet flexible, to monitor and revise risk models, and to use resources proactively in the face of disruptions or pressures of ongoing activities such as learning, control, production, service, trade or industry. Resilience addresses also to an ability to recover from, or building new positions to, misfortune or adaption of mandatory change. The term "resilience" includes typically four abilities: 1) to plan and prepare, 2) absorb disturbance, 3) recover from, and 4) adapt to known or unknown threats. In this study, the empirical and multidisciplinary R\&D results point to the rather practical basis of the term "resilience" and necessitate revisions of its theory, related to such as described in [16] and genealogies of resilience [17].

In the operative environment of this study, higher education institutions are traditionally focused as contributors of new knowledge [18] and competence-professional development [1]. Humboldtian model of higher education and high value returns is addressed in the following studies: development of services [5]; technology and policy [12]; co-creation as manner [19]; value-building [20]; high-value economic returns and cooperation [21]; systemic utility production [22]; path-dependency [23]; and living-labs [24]. In this study, expected new advances are taking place regarding cooperation in emergent value networks (see Fig.1), co-created innovation, the contribution of pioneering innovations, and regional development affecting social and global 
development. The term "co-creativity" is understood as collaboration and described as the "secret to breakthrough creativity" [19]. Learning is placed in collaboration with innovation systems and living-labs [24]. A last-mile research approach for general utility production in the end addresses the value-building and economic returns on a national-global scale [22]. An integrative learning space and examples of the use of the research methodology as continuums of the integrated R\&D related learning in the context of international safety and security $R \& D$ projects as described in [5].

The original foundation of higher education and its various ways of learning has a long tradition. For example, a strong resonance for this operational capability and resilient learning and training theme can be found far behind Dewey's Democracy and Education, where he said, "Education is not an affair of telling and being told, but an active and constructive process ... Its enactment into practice requires that the school environment be equipped with agencies for doing, with tools and physical materials, to an extent rarely attained. It requires that methods of instruction and administration be modified to allow and to secure direct and continuous occupations with things" [25] [p.33]. Dewey explained learning from the perspective of passive absorption to learning by doing; here, this "doing" is R\&D-related and learning by more resilient direct contact with things as well as learning through real-life contexts, inquiry, simulations, and training for an adaptive reasoning and action competence. Dewey's classical educational theories and models had large-scale influence on later views of learning. Almost none of the reviewed learning approaches in this study is thought to be totally new, but rather is seen as paths and mind resonance with Dewey, such key literature as: pedagogic creed [26] and the theory of inquiry [27].

\section{Methodology}

In this study, the multiple case study approach was used, and the research setting of the study addresses the following literature: "the case research strategy in studies of information systems" [28]; "building theories from case study research" [29]; "case studies and theory development in the social sciences" [30]; "qualitative data analysis" [31]; "real world research" [32]; and "case study research design and methods" [33]. In this analysis, the multiple case studies followed replication logic, and the selected cases served in a manner similar to multiple experiments, with similar results. A literal replication or contrasting results in a theoretical replication predicted explicitly at the outset of the investigation. The case study analysis used herein brings an understanding of a complex issue and object, and can extend experience or add strength to what is already known through previous research and reviewed literature. Here, case studies emphasize a detailed contextual analysis of a limited number of events or conditions and their relationships when the relevant behaviour is not manipulated and the role of the researcher is that of an "objective outsider," as [34] positioned.

Reference [33] noted that the simplest multiple-case design would involve the selection of two or more cases that are believed to be literal replications, while a more complicated multiple-case design would result from more and different types of new 
theoretical replications, such as the theoretical aspects of learning paths by scopes, deliverables and resilience represents, as according to [30] earlier [29] guidance for theory building. In this study, the end of data collection and analysis was indicated by saturation, when no new information emerged for the research purpose [35].

The data collection of this study is cumulative and systematically used for a qualitative analysis, where (n) indicates an instance of data collection used for this analysis between January 2008 and March 2017. The data collection is comprised according to the results descriptions by Finnish Academia including eighteen $(n=18)$ cumulative categories: 1) scientific publication $(\mathrm{n}=52)$ according to publication forum classification; 2) number of open data collections $(n=3)$ facilitated and licensed data collections used; 3) collective creation of international publication $(n=72)$ articles; 4) data of international researcher exchange; 5) integration of education $(n=6)$ study units related $(n=3)$ theses and $(n=3)$ dissertations; 6$)$ data of European Commission's funded research projects $(n=4)$ in FP7 \& H2020, data of national funded strategic research projects $(n=1)$ and data of new applications for H2020 funding (involved cases descried more detailed in next chapter); 7) presentations and audiences with $(n=56)$ stakeholders; 8$)$ data of $(n=4)$ workshops and $(n=6)$ seminars, creation of $(n=4)$ events for research and development; 9) participation to public audiences, such as in a parliament and participation to statements $(n=1) ; 10)$ publication in $(n=6)$ newspapers and general descriptions according to publication forum classifications; 11) invited $(\mathrm{n}=3)$ presentations; 12) indicators of social media: Twitter, LinkedIn, Facebook and $(n=3)$ homepages; 13$)$ support of public events for international, national, and regional audiences; and data of economic indicators, such as 14) investigations, 15) patents, 16) licenses, 17) spin-offs, and 18) start-ups.

\section{Description of Cases}

The data collection category namely R\&D projects for qualitative analysis included followed: the two TEKES funded R\&D projects $(n=2)$, namely RIESCA and SATERISK; the four $(\mathrm{n}=4)$ security-related European Commission FP7 or Horizon funded R\&D projects, namely PERSEUS, ABC4EU, EU_CISE_2020 and MARISA; and the data gathering of Academy of Finland Strategic Research Council's Programme's Security in a Networked World project $(n=1)$, namely From Failand to Winland, communicated on Twitter as \#WINLandFI.

RIESCA: Rescuing of Intelligence and Electronic Security Core Applications [Funded by TEKES: October, 2007 to March, 2010] was the first of our externally funded R\&D projects. The research of RIESCA addresses a number of systems, such as transport and logistics, power and telecommunication, hydropower and nuclear power stations, which are critical to the day-to-day functioning of any technologically advanced society, such as Finland. When assessing possible risks, it is only seldom taken into account that power, hydropower and nuclear power plants are critically dependent on the reliability and security of information systems. The aim of RIESCA was to offer contributive and constructive solutions, such as design-based solutions, to this problem. The student-centered R\&D and novel resilience viewpoint was integrat- 
ed in RIESCA: an individual student or larger student groups were assigned to defined parts of the project. There are two notable advantages conferred by the use of students on the project, namely: 1) confidential information management can be used and developed in study units and; 2) the students acquire more new professional expertise that fits with the principles of R\&D framework. In view of collaboration, the trust-based networked expertise relationships were achieved in RIESCA.

SATERISK: Risks of Satellites and Satellite Tracking System [Funded by TEKES]. The idea to study risks related to satellites was created by students of Laurea in 2008. Funding from TEKES was secured on 14.11.2008 and allocated for the period 1.9.2008 to 31.8.2011. The goal of SATERISK was to study the risks connected to satellite tracking and to ascertain if the use of satellite tracking can generate further risks. The project analyses risks using different approaches: legal, technical and mode of use; it will also study potential future requirements and risks. SATERISK has expanded into an academic multi-disciplinary collaboration with the University of Lapland, ITMO in St. Petersburg, Russia and the BORDERS network, coordinated by the University of Arizona, USA. Here it is noteworthy that SATERISK inspired students' resilient scope thinking and gave the possibility for something else to emerge; SATERISK temporarily moved students' minds far away from daily official routines and responsibilities. This clearly advanced the aspects of motivation. SATERISK also demonstrated that a student's expertise itself and student-workplace relations can trigger externally funded $R \& D$ projects.

PERSEUS: Protection of European Borders and Seas through the Intelligent Use of Surveillance [Project ID 261748; Funded under FP7-SECURITY] was coordinated by INDRA Sistemas with $n=29$ partners. The timeframe of the PERSEUS research was between January 2011 and December 2014. In this study, the selection of PERSEUS as a case represents a program and research consortium that aims at the large-scale integration, validation, and demonstration of novel systems and symbolizes European research collaboration, providing a federative frame to join research and steering in areas of significant European interest. In this study, the focus of the PERSEUS investigation was in resilience and adaption of consortium functions and research on international knowledge transition and path-dependency mechanisms, dissemination, and events.

ABC4EU: Automated Border Control Gates for Europe [Project ID 312797; Funded under FP7-SECURITY] is a European Union wide R\&D project and involves a Consortium of 15 partners from 8 different countries. The purpose is to make border control more flexible by enhancing the workflow and harmonizing the functionalities of automated border control gates. The project started in January 2014 and will last for 42 months. It is led by INDRA Sistemas S.A. from Spain. In recent years, many ABC Gates have been deployed in the main European airports, most of them as pilot projects intended to test their capability to improve the border crossing processes in aspects such as speed, security, automation, and false rejection reduction. In particular, resilience management and harmonization would be required in areas as epassports management, biometrics, gate design, human interface, parallel processes, signalling, and interoperability. 
EU_CISE_2020: European Union's Information Sharing Environment [Project ID 608385; Funded under FP7-SECURITY] addresses steps forward along the accomplishment of the European roadmap for Common Information Sharing and Distributed Systems and Services Environment. The project attains the widest possible experimental environment of innovative and collaborative services and processes between European maritime institutions and takes as reference a broad spectrum of factors in the field of European Integrated Maritime Surveillance, arising from the European legal framework, as well as from studies, pilots, and related R\&D projects. The timeframe of EU CISE 2020 is between 01/06/2014 and 01/06/2018.

MARISA: Maritime Integrated Surveillance Awareness [Project ID 740698; Funded under H2020] is new H2020 project, timeframe between April 2017 and September 2019. The overarching goal of this project is to provide the security communities operating at sea with a data fusion toolkit, which provides a suite of methods, techniques and software modules to correlate and fuse various heterogeneous and homogeneous data and information from different sources, including Internet and social networks, with the aim to improve information exchange, situational awareness, decision-making, reaction capabilities and resilience. The expected solution will provide mechanisms to get insights from any big data source, perform analysis of a variety of data based on geographical and spatial representation, use techniques to search for typical and new patterns that identify possible connections between events, explore predictive analysis models to represent the effect of relationships of observed object at sea. Enterprise and ad-hoc reporting and Maritime Services, within the CISE context, will be provided to support users and operational systems in their daily activities, as well as presentation tools for navigating and visualizing results of data fusion processing.

\#WINLandFI: From Failand to Winland, the Academy of Finland Strategic Research Council [Funding ID 303623; from April 2016 to March 2019] as ongoing Critical Research Project. This research project will take you from Failand (failed future Finland) to Winland, e.g., Finland where key security threats have been responded to with resilient policy-making. The starting point of research is the question, "What kinds of security risks and threats could paralyse Finland so fundamentally that our country becomes Failand?" The proposal included arguments that Failand becomes reality if two of the most fundamental elements of a functioning society fail: food security and energy security, which both are closely linked to water security. In addition, the proposal surmises that such failure is likely to result from the sum of three key components: long-term pressures, shocks and surprises, and policy responses. Addressing such an equation, and guiding the way to Winland, requires a multidisciplinary team that works together in an inter- and transdisciplinary manner, involving the key stakeholders throughout the process. \#WINLandFI consortium have paid focused attention to establish an integrative research and stakeholder process that will utilise a combination of scenario planning and decision analysis, supported by a series of co-creation workshops and other interaction methods. With the help of these scenarios; \#WINLandFI consortia will study how water, food, and energy-related pressures, shocks and surprises, and policy responses affect Finland's overall security. 


\section{$4 \quad$ Research Findings}

Focusing on regional and national development and R\&D is a significant purpose for all higher education institutions in Finland. In the past few years, the structural reform of higher education in Finland is represented, and this reform has been widely and actively discussed nationally in order to develop the national and regional innovation system and to clarify the shared nature of the higher education system. This produces new, collaborative knowledge and competence and searches for creative solutions for focused problems and challenges at various levels and project continuums. The importance of $R \& D$ integration is clearly emphasised when combining regional competence, participating in networks, and utilising different partnerships in shared $R \& D$ processes. The functions of $R \& D$ at all higher education institutions can be reasoned by a purposeful and experiential approach, as producing expertise in processes of knowledge transfers, transformations, and catalyses related resilient learning aspects.

The term "high-value impact" addresses the amount of realized economic and social value as well as achieved value and impact returns, which are created by applying knowledge generated by a research consortia and R\&D collaboration. The study revealed that the terms "value", and achieving "high-value impacts", are in line with the concept of value concentration where values are related to knowledge and where they produce outcomes described as revised concept of value concentration. The concentration quartet includes the following: 1) academic value as intellectual property, 2) value of research, 3) value of education, and 4) empiric value, (described later in Fig.1). Here, the term "empiric value" addresses value returns by disseminated artifacts, services, and value concentrations for competitiveness-business and policy development related reasoning.

One micro-level purpose and contribution of this study addresses the form and development of higher education that focuses on the demands of the individual-nationalglobal comprehensive security domain. Here, teachers, policy, and authority representatives work and interact more closely together as a collective learning community that involves students (legitimate peripheral participation) and the implementation of study units in higher education and shared R\&D. This shared R\&D includes learning by national-international research consortiums and work packages as realizations, such as in manners of catalytic and adaptive acquisition, participation and co-creation, e.g., manners of R\&D and more resilient learning for building something new: resonance with towards realization of research and development [5] and creating entrepreneurial universities [1].

Furthermore, this study contributes to the understanding and mind of the resilient learning in the view of term "scope", such as "research-learning scope", which can be useful for interactions of an "resilient-elastic nature" and for focusing on the meaningfulness of learning integration, learning paths, and creativity, especially in the perspective of a student's integration into R\&D and regional-national development.

The study recorded first that the terms "scope" and "resilient steering" (see Fig.1) were useful to a satisfaction, atmosphere, mutual trust, confidence, and "learning to like or dislike" in a learning space (such as integrated consortia environment) where a 
student takes "a scope" and makes his own personal activity, creation, improvement, and validation into the selected or shared learning target as "shared scope", e.g., as in a new application building process, which resulted from scope-based thinking. Second, a "scope" was not loaded by a teacher's knowledge in the beginning of studies, so scope-related knowledge can be composed openly by a student's viewpoints as by resilient-elastic nature, interests, aspiration, and motivation, not necessary only in teacher's or problem-based viewpoints. Third, the term "research-learning scope" can refer to a mental or physical target or subject matter that something deals with in learning. Fourth, the aim of using the "resilient-elastic scopes" in the beginning of R\&D related learning integration as frame to support a student's imagination and creativity in learning, and the assumption was that the understanding of resilience relations and "resilient-elastic nature of scope" would generate and maintain the motivation and spirit for learning, balancing the judgments and potentials of objectives, goals, and targets; e.g., the tuning of a cognitive load in a lifetime of studies would be balanced by students and teachers by "alignment and adjusting of scopes". Fifth, the "scope" addresses the idea that, between two people, there is third dimension as "a scope", e.g., a model, artifact, tool, concept, or mental or social factor with which students may share, transfer, adapt, and build knowledge. It communicates, activates, and motivates their personal or team learning spirit and confidence. Sixth, "the scope" increases resilience, "everything does not go as designed" and elasticity in solution based learning approach, both can be approached in the reactive and proactive sense. And lastly, "the design of scopes" bridges "learning by novel research agenda" and "motivation of learners" in the first place and builds furthered components for continuums of using new proposed knowledge sources as with theory and metaphors of learning in action-related competences.

It is noteworthy that new and small enterprises, particularly knowledge-intensive ones, are involved as legitimated actors [3] in the innovation system. In this view, higher education institutions are seen as significant producers of new knowledge and competences, and users of the latest findings and bodies of knowledge in action, which gives them a role within the thematic center as collectors of the innovation system (see Fig.1). Their thematic nature comes from their operative action and resilience as capability in combining knowledge from several sources, such as lead innovation systems, or institutions such as strategic centers of excellence in science, technology, and systemic innovations. In addition, multiple helix cooperation [21] ensures a body of knowledge is co-created with other organizations to contribute to innovations in industry and society as a whole, e.g., national strategic research agenda.

The central challenges faced by the realization of the shared R\&D functions and resilience viewpoints in higher education consisted of the following: 1) the establishment of new management forms and culture and control of the mass of projects through the R\&D realizations and by higher education institutions, with mutual trust and confidence; 2) the balancing and modularizing of the cognitive load and the challenges of learning in R\&D realizations; 3) pedagogical development and continuous, relatively adaptive-resilient change in $R \& D$ that pose great challenges for teachers and management; 4) understanding of the meaning of student-centred R\&D in communities of work and workplaces as research for work (see relevance to work in 
Fig.1); 5) ethics management and issues; 6) the development of incipient internationalization and individual-global interactions; 7) the measurement of the effects and development of utility, usability, and strategic measurement as an evaluation design structure in higher education; and 8) dissemination of the new R\&D-related learning model and ethic for sustainability manners in the context higher education and helix integration.

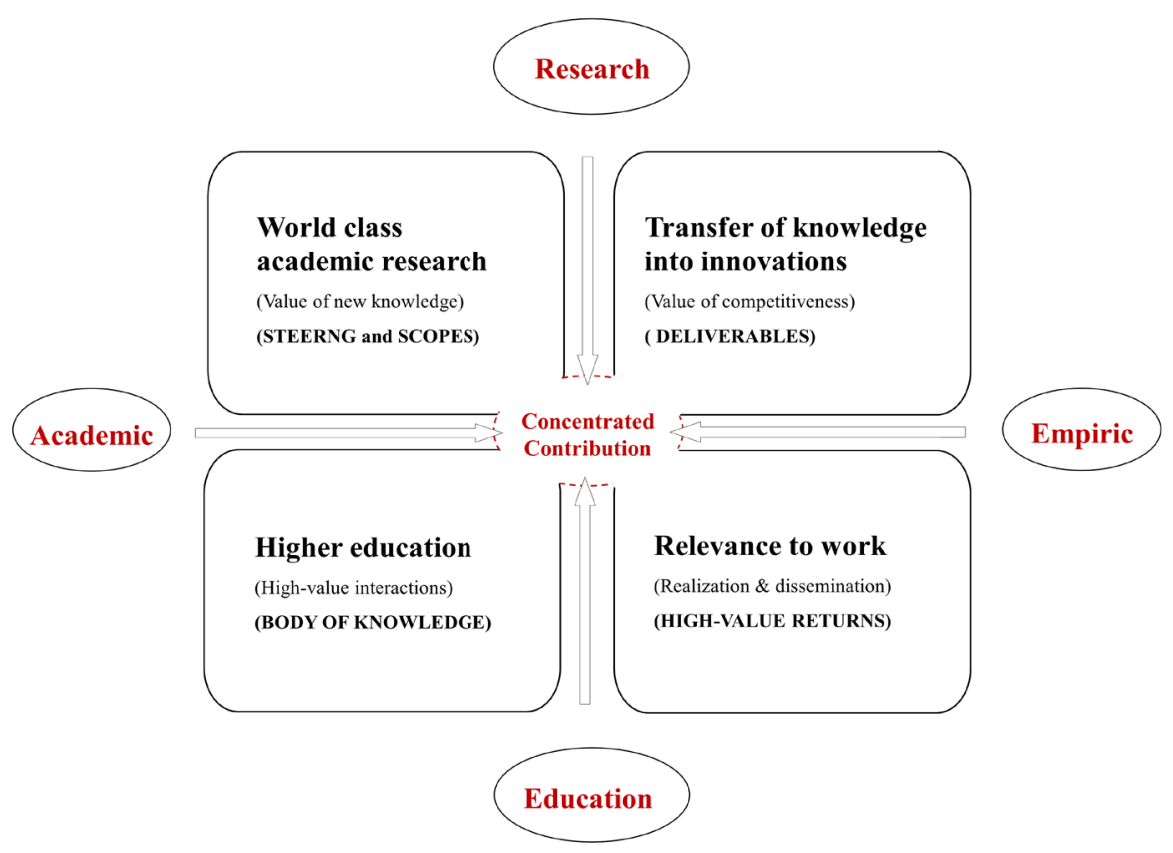

Fig. 1. The revised concept of value concentration (Pirinen, 2013 p.70).

In the perspective of security management-related higher education, a regionalnational capacity to provide security-related knowledge-competence-capability pathways and knowledge interconnections depends on the ability to continuously innovate in order to ensure technological leadership and be a credible networking partner for concentrated contribution. The study revealed that resilience related research is necessary in future studies. Hence, current and emergent challenges can be remarked such as the recent dramatic falls in investment in R\&D and risk management undermining efforts to support the security and sector, broader defence, and security goals. In this security view, one piece of advice for future study is that creativity and innovative learning scopes should be more systematically designed and adopted for research, development, and innovation activities in the context of current knowledge, competence, capability, and performance (action competence) settings. Hence, the creativity and innovation approach steers $\mathrm{R} \& \mathrm{D}$ process planning towards increasingly participatory, dynamic, and creative forums of new competence production and will enhance learning and resilience.

The comprehensive security-related $\mathrm{R} \& \mathrm{D}$ integration as concept of value concentration (described in Fig.1) has a high value impact on pedagogy, which is delivered 
in students' knowledge, competence, and capability building processes. The crucial factors as deliverables are not only subject-specific competence, but also a researchoriented developmental approach, interaction skills, the ability to encounter colleagues, students, and partners dialogically, and having the pedagogical, participation and leadership competence. The qualities of an expert in deliverables promote the implementation of good, high-quality teaching, and foster students motivation, participation, and dignity. From the students' points of view, the emphasis is on motivation, spirit, dignity, guidance, learning process, mutual reflection, professional and human growth, and a research-oriented, developmental approach to own and organization work.

\section{Discussion and Remarks}

The comprehensive security-related education and new pedagogical solutions have possibilities to further current R\&D activities in ways that bring creativity and innovation-building related knowledge towards competence-capability, as well as sustains performance (resilience and competence). The academia-consortium and external funding structures of research activities already exist, as investigated here. However, the comprehensive security integration does need more action competence and capability-related understanding, followed by future studies.

There are many reasons for future progress and discussion of the term "resilience", such as: the number of systems, interconnections, and transaction elements increases over time; the system complexity increases and the resulting interactions become challenging to maintain, e.g., the number of updates, difficulties in using and facilitation, life cycles, continuity management, and for understanding emergent relations between the terms "resilience", "elastic", "robustness", "complexity", and "persistence". In this context, the term "resilience" would be first related to the term "robustness". In this setting, as previously mentioned, the term "robustness" addresses "the degree to which a system is able to withstand an unexpected internal or external event or change without degradation of in system's performance." Then, the term "robustness" indicates "the degree to which system operates correctly in the presence of exceptional conditions." On the other hand, "resilience" refers to the system's ability to recover, retrieve, restore, or regenerate its performance after unexpected impact that declined its performance, as [36] proposes.

In this context, as understood so far, the significance of the term "resilience" addresses the ability of a system, community, or society exposed to security-related threats to resist, absorb, accommodate, and recover from the effects of a threat in a timely and efficient manner, including through the preservation, restoration, and adaption of its essential basic structures and functions to state that it is possible to going on and continuity. Regardless, the term "resilience" includes strong relations to reactive nature in included R\&D cases and literatures, e.g., respond, recover, retrieve, restore, and adapt. Our furthered research-learning-scope includes many proactive dimensions, such as "prepare, prevent, configure, and protect". Currently in \#WINLandFI, there are ongoing discussions of resilience and stability of ecological systems [16], 
community and mechanisms of critical and resilient digital services [37], resilience in globalization and transitional pathways [38], genealogies of resilience [17], from systems ecology to the political economy of crisis adaptation and management and resilient systems [39], and resilience engineering [40].

The relation between the terms "learning scope" and "resilience" in this study was imperative because it can be expected to further our surviving capabilities by related changes on demand and furthering of novel learning designs and curriculums. This resilient learning design with address what we need to study when faced with inevitable difficulties, such as often scopes described in national research agenda and H2020 calls: as grounded so far, the emerging term "resilience" is approached for achievements of surviving capabilities for changes on demand and manners to enhance the capability at all levels of activities to create paths that are robust yet flexible, to monitor and revise risk models, and to use resources proactively in the face of disruptions or pressures of ongoing activities such as learning, control, production, service, trade or industry. Resilience addresses also to an ability to recover from, or building new positions to, misfortune or adaption of mandatory change. The term "resilience" includes typically four abilities: 1) to plan and prepare, 2) absorb disturbance, 3) recover from, and 4) adapt to known or unknown threats. In this study, the empirical and multidisciplinary R\&D results point to the rather practical basis of the term "resilience" and necessitate revisions of its theory, related to such as described in [16] and genealogies of resilience [17].

RESILIENCE OF KNOWLEDGE ECONOMY: The discussion of a "knowledge economy" can be addressed here the use of knowledge-intensive technologies and services, such as: information sharing; knowledge sources, knowledge co-creation, and knowledge management to produce information-intensive economic benefits as well as new workplace creation integrated into R\&D-related themes. In macro scale, the global economy is transitioning to a "knowledge economy" or "resilient knowledge economy"; in micro scale, higher education is transitioning to a "knowledge economy of more resilient information-intensive services, products, artifacts, policy developments, and methodologies which are achieved in R\&D related regional-global collaboration" [5] as well as transitions between knowledge acquisition, participation, and knowledge building and co-creation more resilient learning metaphors.

TOWARDS REASONING OF RESILIENT LEARNING: During the security systems evolution, while each of the systems for digitalization and integration may formally go through the development process, such as readiness requirements, the overall integration analysis, development, and corresponding requirements are clearly increasing due to the following elements which are ever more present: 1) operational and managerial independence of operations; 2) commercial value of data and data fusion; 3) challenges of border and cultural traits; 4) emergent strategies and behaviour; 5) trust building, e.g., over borders and between authorities and vary silos; 6) ethics management and social aspects, e.g., citizen's responsibility and organization's mutual and national responsibility; and 7) path-dependency in evolutionary, developmental, and cultural views. 
TOWARDS RESILIENT LEARNING: The study exposed that the terms "scope", "motivated steering", "social characters of involvement" were useful to a satisfaction, atmosphere, mutual trust, confidence, and "learning to like or dislike" in a resilient learning space in such as integrated $R \& D$ consortiums where; a student can take "a scope" and makes his own personal activity, creation, improvement, and validation into the selected or shared learning target as "shared scope", e.g., as in a new application-proposal building or co-creation process, which resulted from scopeparticipation-based thinking.

TRIGGER OF RESILIENT LEARNING: A scope and thematic setting of study triggers (steering) drivers was not loaded by a teacher's knowledge in the beginning of studies, so scope-related knowledge can be composed openly by a student's viewpoints as by resilient-elastic nature, interests, aspiration, and motivation, not necessary only in teacher's or problem-based viewpoints.

TARGET AND SUBJECT ORIENTATION: The term "research-learning scope" can refer to a mental or physical target or subject matter that something deals with in resilient learning. The target of using the "resilient-elastic scopes" in the beginning of $\mathrm{R} \& \mathrm{D}$ related learning integration as frame to support a student's imagination and creativity in learning, and the assumption was that the understanding of resilience relations and "resilient-elastic nature of scope" would generate and maintain the motivation and spirit for learning, balancing the judgments and potentials of objectives, goals, and targets; e.g., the tuning of a cognitive load in a lifetime of studies would be balanced by students and teachers by "alignment and adjusting of scopes and subject matters".

KNOWLEDGE BUILDING ARTIFACTS: The "scope" addresses the idea that, between two people, there is third dimension as "a scope", e.g., a model, artifact, tool, concept, or mental or social factor with which students may share, transfer, adapt, and build knowledge. It communicates, activates, and motivates their personal or team learning spirit, confidence and stimulates peripheral participation.

ENHANCED RESILIENCE: Using the scope as learning trigger-driver increases resilience, "everything does not go as designed" and elasticity in solution based learning approach, both can be approached in the reactive and proactive sense. The design of scopes bridges "learning by novel research agenda" and "motivation of learners" in the first place and builds furthered components for continuums of using new proposed knowledge sources as with theory and metaphors of learning in action-related competences.

TOWARDS SHARED RESILIENT LEARNING IN EUROPE: Collective development forums of European Higher Education Area discusses challenges of higher education institutions and recommends that higher education take on more of a leadership role as actors and pioneers of the innovation system and national-global development progress. According this study, it is evident that higher education institutions, especially in security-related fields, have to be supported by multidisciplinary and transdisciplinary cooperation with business communities and universities, for activation of competence, capabilities, performance, adaptions on demand, and social dialogue. 
Paper-Resilient Learning - Towards Integration of Strategic Research Programmes, Higher Education...

\section{References}

[1] B. Clark, Creating Entrepreneurial Universities: Organizational Pathways of Transformation, Bingley: Emerald Group Publishing Limited, 2007.

[2] B. Asheim, "The changing role of learning regions in the globalising knowledge economy, "Regional Studies, vol. 46, pp. 993-1004, 2012. https://doi.org/10.1080/00343404. 2011.607805

[3] J. Lave and E. Wenger, Situated learning: Legitimate peripheral participation, Cambridge: University Press, 2009.

[4] R. Pirinen, "Externally Funded Research and Development Projects in Perspective of Learning,” International Journal of Engineering Pedagogy, vol. 3, pp. 27-36, 2011. https://doi.org/10.3991/ijep.v1i3.1806

[5] R. Pirinen, Towards realization of research and development in a university of applied Sciences, dissertation, Kuopio: University of Eastern Finland, 2013.

[6] R. Pirinen, "Research framework of integrative action," in Americas Conference on Information Systems, San Francisco, 2009.

[7] M. Gibbons et al., The new production of knowledge, Los Angeles: Sage Publications, 2008.

[8] D. Kolb, "The process of experimental learning," in The process of experimental learning, D. Kolb Ed. New Jersey, Prentice-Hall, 1984, pp. 19-38.

[9] J. Mezirow, "Critical theory of adult learning and education," Adult Education, vol. 32, pp. 3-24, 1981. https://doi.org/10.1177/074171368103200101

[10] R. Revans, The origins and growth of action learning, Bromley: Charwell-Brat, 1982.

[11] Y. Engeström, Learning by expanding: an activity-theoretical approach to developmental research, Helsinki: Orienta-Konsultit Oy, 1987.

[12] V. Harmaakorpi, Building a competitive regional innovation environment: the al development platform method as a tool for regional innovation policy, dissertation, Helsinki: University of Technology: Monikko, 2004.

[13] R. Schaefer, The school as a center of inquiry, New York: Harper and Row Publishing, 1967.

[14] A. Sfard, "On two metaphors of learning and the dangerous of choosing just one," Educational Researcher, vol.27, pp. 4-13, 1998. https://doi.org/10.3102/0013189X027002004

[15] L. S. Vygotsky, "Interaction between learning and development.," in L.S. Vygotsky mind in society, M. Cole et al., Eds. Cambridge, Harvard University Press, 1978, pp. 79-91.

[16] S. Holling, "Resilience and stability of ecological systems," Annual Review of Ecology and Systematics, vol. 4, pp. 1-23, 1973. https://doi.org/10.1146/annurev.es.04.110173 .000245

[17] J. Walker and M. Cooper, "Genealogies of resilience: from systems ecology to the political economy of crisis adaptation," Security Dialogue, pp. 143-160, 2011. https://doi.org/10.1177/0967010611399616

[18] M. Scardamalia and C. Bereiter, "Knowledge building: Theory, pedagogy and technology," in Cambridge handbook of the learning sciences, K. Sawyer, Ed. Cambridge: University Press, 2006, pp. 97-118.

[19] R. West, Communities of innovation: Exploring collaborative creativity within a community of graduate instructional designers, dissertation, University of Georgia, 2009.

[20] K. Sawyer, Group genius: The creative power of collaboration, Cambridge: Perseus Books Group, 2008.

[21] H. Etzkowitz et al., Capitalizing knowledge. New Intersections of Industry and Academia, New York: State University of New York Press, 1998. 
Paper-Resilient Learning - Towards Integration of Strategic Research Programmes, Higher Education...

[22] J. Nunamaker and R. Briggs, "Toward a broader vision for information systems," ACM Transactions on Management Information Systems, vol. 2, pp. 1-12, 2011. https://doi.org/10.1145/2070710.2070711

[23] R. Nelson and S. Winter, An evolutionary theory of economic change, Cambridge: Harvard University Press, 1982.

[24] A. Ståhlbröst, Forming future IT: The living lab way of user involvement, dissertation, Luleå: University of Technology, 2008.

[25] J. Dewey, Democracy and Education: An Introduction to the Philosophy of Education, New York: Macmillan, 1916.

[26] J. Dewey, "My pedagogic creed," in The essential Dewey: Pragmatism, education, democracy, L. Hickman and T. Alexander, Eds. Bloomington: Indiana University Press, 1897, p. 229-235.

[27] J. Dewey, Logic: The theory of inquiry, New York: Henry Holt and Company, 1938.

[28] D. Benbasat, et al., "The case research strategy in studies of information systems," MIS Quarterly, vol 11, pp. 369-386, 1987. https://doi.org/10.2307/248684

[29] K. Eisenhardt, "Building theories from case study research," Academy of Management Review, vol. 14, pp. 532-550, 1989.

[30] L. George and A. Bennett, Case studies and theory development in the social sciences, Massachusetts: MIT Press, 2005.

[31] M. Miles and A. Huberman, Qualitative data analysis: an expanded sourcebook, Thousand Oaks: Sage Publications, 1994.

[32] C. Robson, Real world research, Oxford: Blackwell Publishing, 2001.

[33] R. Yin, Case study research design and methods, Thousand Oaks: Sage Publications, 2009.

[34] K. Herr and G. Anderson, The action research dissertation: A guide for students and faculty, Thousand Oaks: Sage Publications, 2005.

[35] J. Corbin and A. Strauss, Basics of qualitative research: techniques and procedures for developing grounded theory, Los Angeles: Sage Publications, 2008.

[36] A. Kott and T. Abdelzaher, "Resiliency and Robutness of Complex Systems and Networks," in Adaptive, Dynamic, and Resilient Systems, Boca Raton, Taylor \& Francis Group, 2014, pp. 67-85.

[37] R. Pirinen, "Mechanism of Critical and Resilient Digital Services for Design Theory," in International Conference on Computer Science, Computer Engineering and Social Media, Lodz, Poland, 2015. https://doi.org/10.1109/cscesm.2015.7331874

[38] G. Wilson, "Community resilience, globalization, and transitional pathways," Geoforum, pp. 1218-1231, 2012. https://doi.org/10.1016/j.geoforum.2012.03.008

[39] N. Suri and G. Cabri, Adaptive, Dynamic, and Resilient Systems, Boca Raton: Taylor \& Francis, 2014

[40] N. Atooh-Okine, Resilience Engineering Models and Analysis, New York: Cambridge University Press, 2016. https://doi.org/10.1017/CBO9781139026772

\section{$7 \quad$ Author}

Rauno Ilmari Pirinen is with Laurea University of Applied Sciences, Espoo, Finland (rauno.pirinen@laurea.fi).

Article submitted 10 March 2017. Published as resubmitted by the authors 31 March 2017. 